\title{
Antifungal susceptibility and distribution of Candida spp. isolates from the University Hospital in the municipality of Dourados, State of Mato Grosso do Sul, Brazil
}

\author{
Adriana Araújo de Almeida ${ }^{[1]}$, Cristiane Suemi Shinobu Mesquita ${ }^{[2]}$, \\ Terezinha Inez Estivalet Svidzinski ${ }^{[2]}$ and Kelly Mari Pires de Oliveira ${ }^{[1]}$
}

[1]. Laboratório de Microbiologia Aplicada, Faculdade de Ciências Biológicas e Ambientais, Universidade Federal da Grande Dourados, Dourados, MS. [2]. Laboratório de Micologia Médica, Departamento de Análises Clínicas, Universidade Estadual de Maringá, Maringá, PR.

\begin{abstract}
Introduction: Hospital infections caused by Candida spp. are a leading cause of morbidity and mortality in hospitalized patients, particularly those that are critically ill or immunocompromised. In this study, the distribution of Candida species in isolates from the University Hospital of the Federal University at Grande Dourados and their in vitro susceptibility to antifungal drugs were analyzed. Methods: Yeasts were phenotypically identified using classical methodologies. Antifungal susceptibility tests to amphotericin B and fluconazole were performed using the broth microdilution technique. Results: A total of 50 Candida isolates were obtained from hospitalized patients during the study period. We analyzed yeast isolates from urine $(\mathrm{n}=31 ; 62 \%)$, blood $(\mathrm{n}=12 ; 24 \%)$, and tracheal secretions $(\mathrm{n}=7 ; 14 \%)$. The following Candida species were identified: C. tropicalis $(\mathrm{n}=21$; $42 \%), C$. albicans $(\mathrm{n}=18 ; 36 \%)$, . glabrata $(\mathrm{n}=10 ; 20 \%)$, and $C$. krusei $(\mathrm{n}=1 ; 2 \%)$. Antifungal susceptibility tests demonstrated that $C$. albicans was susceptible to both antifungal agents. However, $31.2 \%$ of the non-C. albicans Candida isolates displayed dose-dependent susceptibility to fluconazole, and $3.1 \%$ were resistant to amphotericin B. Conclusions: In contrast to previous reports, our results indicated that $C$. tropicalis was the most commonly isolated yeast species among the hospital patients. The predominance of non-C. albicans Candida infections confirms the importance of species-level identification for implementing appropriate antifungal therapies.
\end{abstract}

Keywords: Candida. Candiduria. Candidemia. Amphotericin B. Fluconazole.

\section{INTRODUCTION}

Fungal hospital infections (HI) have increased worldwide in recent decades, which likely reflects advances in medical practices such as the increasing use of invasive procedures for diagnosis and treatment as well as the increasing number of immunocompromised patients at high risk for fungal infections ${ }^{1}$.

According to Azie et al. ${ }^{2}$, yeasts of the genus Candida are responsible for approximately $70 \%$ of all hospital-environment fungal infections. Therefore, Candida species are of enormous clinical importance because of the high frequencies at which they colonize and infect humans and cause diseases ranging from lesions in the mucous membranes and skin (superficial) to infections in body organs (and their resulting spread through the bloodstream, which characterizes invasive candidemia) ${ }^{3}$.

Address to: Dra. Kelly Mari Pires de Oliveira. Rodovia Dourados-Ithaum, km 12, 79804-970 Dourados, MS, Brasil.

Phone/Fax: 5567 3410-2220

e-mail: kellyoliveira@ufgd.edu.br

Received 17 December 2012

Accepted 22 May 2013
Candida spp. are commensal microorganisms that inhabit various sites in the human body (including the gastrointestinal and respiratory tracts) and comprise part of the vaginal and urethral microbiota ${ }^{4}$. These microorganisms can become pathogenic, however, as a result of alterations in host defense mechanisms or breakdown of anatomical barriers in the body situations that are common in hospitalized patients who receive antibiotics or undergo frequent invasive procedures ${ }^{5}$.

Hospital infections attributed to Candida spp. are responsible for increases in morbidity and mortality among hospitalized patients, particularly those that are critically ill or immunocompromised. The origins of these infections can be endogenous (due to yeast proliferation or dislocation) or exogenous (by transmission of microorganisms from the hospital environment through contact with health workers) ${ }^{3}$.

Studies in Brazil that have focused on the epidemiology of infections caused by Candida species have reported that C. albicans is the most frequently isolated species of the genus. There have been, however, increases in HI caused by nonC. albicans Candida (NCAC) species such as C. tropicalis, C. glabrata, C. parapsilosis, and C. krusei ${ }^{6-8}$. The occurrence of infections caused by these yeasts is relevant to $\mathrm{HI}$ vigilance because these micro-organisms have varying virulence attributes and profiles of antifungal drug sensitivity, including recent reports of resistance to the principal antifungal drugs currently administered in hospitals ${ }^{9,10}$. 
Amphotericin B and fluconazole are among the antifungal agents most widely used in treating systemic fungal infections. The former is an efficient polyene antifungal agent, although its use is limited due to its high degree of toxicity in humans. The latter compound is a triazole frequently prescribed to treat Candida spp. infections because of its excellent patient tolerance and minimal side effects ${ }^{11}$, although a number of species of Candida display fluconazole resistance ${ }^{12,13}$ and the growing worldwide use of this drug to treat candidemia is one of the principal causes of the recent increase in the prevalence of NCAC species ${ }^{14}$.

Because of the importance of identifying the Candida species involved in $\mathrm{HI}$ and their increasing resistance to antifungal agents, the present study analyzed the distribution of Candida species in the University Hospital of the Federal University at Grande Dourados and evaluated the yeasts' in vitro susceptibility to antifungal drugs.

\section{METHODS}

We evaluated clinical samples from patients being treated at the University Hospital of the Federal University at Grande Dourados, central-western Brazil, between June 2010 and June 2011. This hospital has 197 beds, including 32 in the intensive care unit (ICU). The following information about the patients was collected: sex, age, the hospital ward in which the patient was being treated when the infectious agent was identified, and mortality during hospitalization, whether attributable to Candida infection or not.

The clinical samples that were tested for Candida species included urine, blood, and tracheal secretions. The samples were cultured according to standard procedures described in the literature. Cultures from urine samples were considered significant at concentrations above $10^{5}$ colony-forming units per milliliter $(\mathrm{CFU} / \mathrm{mL})$.

Yeasts were isolated and initially identified using CHROMagar Candida ${ }^{\circledR}\left(\right.$ Difco $^{\circledR}$, Sparks, MD, USA). Isolates were definitively identified based on their microscopic, macroscopic, and biochemical characteristics as described by classical methodologies, including colony morphology, production of germinative tubes, micromorphological analyses, and carbohydrate assimilation and fermentation tests ${ }^{15}$.

The susceptibility of the yeast isolates to antifungal agents was determined by the broth microdilution method, following the norms of the Clinical and Laboratory Standards Institute (CLSI), document M27-A ${ }^{16}$. The antifungal agents tested were amphotericin B (Squibb Pharmaceutical, Princeton, NJ, USA) and fluconazole (Pfizer Inc, New York, NY, USA.).

The yeast isolates were pre-cultured in Sabouraud Dextrose agar (Difco ${ }^{\circledR}$, Sparks, MD, USA) at $35^{\circ} \mathrm{C}$ for 24 hours. Suspensions were prepared in sterile saline solution $(0.85 \%)$ with yeast concentrations adjusted to 0.5 to $2.5 \times 10^{3} \mathrm{CFU} / \mathrm{mL}$. RPMI1640 (Sigma-Aldrich $^{\circledR}$, St. Louis, MO, USA) culture media was used and was buffered with 3 morpholinopropanesulfonic acid (Sigma-Aldrich ${ }^{\circledR}$, St. Louis, MO, USA) pH 7.0 and supplemented with $2 \%$ glucose.
Each microplate well (Nunclon, Roskilde, SN, DK) contained $100 \mu \mathrm{L}$ of inoculant and one of the 10 antifungal agent concentrations tested; the cultures were incubated at $35^{\circ} \mathrm{C}$ for 48 hours. All tests were performed in triplicate. A standard strain of C. parapsilosis ATCC 22019 was used as a control in the tests. The microplates were analyzed using an Expert plus - ASYS ${ }^{\circledR}$ (Biochrom, Holliston, MA, USA) analyzer (at 490nm).

The minimum inhibitory concentration (MIC) for fluconazole was defined as the lowest concentration of that compound that could reduce fungal growth by $50 \%$; the MIC of amphotericin $\mathrm{B}$ was defined as the lowest concentration of that compound that could impede any visible yeast growth when compared to positive controls (those without added drugs).

The cut-off levels of susceptibility to fluconazole were utilized according to the supplement M27-S3 ${ }^{17}$ : values of MIC $\leq 8 \mu \mathrm{g} / \mathrm{mL}$ indicated the yeast was susceptible, $16-32 \mu \mathrm{g} / \mathrm{mL}$ indicated the yeast was susceptible dose-dependent (SDD), and $\geq 64 \mu \mathrm{g} / \mathrm{mL}$ indicated the yeast was resistant. This document did not consider amphotericin B, so the susceptibility references levels established by Yang et al. were used ${ }^{18}$ : values of MIC $\leq 1 \mu \mathrm{g} / \mathrm{mL}$ indicated the yeast was susceptible, and levels $\geq 2 \mu \mathrm{g} / \mathrm{mL}$ indicated the yeast was resistant.

\section{Ethical considerations}

This research was approved by the Ethics Committee of the University Hospital of the Federal University at Grande Dourados (protocol 050/2010 - CEP/UFGD).

\section{RESULTS}

A total of 50 Candida isolates were obtained from hospitalized patients during the study period, with the following species distributions: $C$. tropicalis $42 \%(\mathrm{n}=21)$, C. albicans $36 \%(\mathrm{n}=18)$, C. glabrata $20 \%(\mathrm{n}=10)$, and C. krusei $2 \%$ $(\mathrm{n}=1)$.

As observed in Table 1, yeast was more frequently isolated from women $(70 \%)$ and ICU patients (58\%). Case fatality rate was $18 \%$. Candida infections were most common in patients older than 61 years $(46 \%)$ and younger than one year $(22 \%)$. Yeasts from tracheal secretions were mainly obtained from women $(85.7 \%)$ aged older than 61 years $(85.7 \%)$.

Table 2 shows that the species most commonly isolated from urine was C. tropicalis (38.8\%), followed by C. albicans $(29 \%)$, C. glabrata (29\%), and C. krusei (3.2\%). Among the isolates derived from blood, C. albicans $(66.6 \%)$ was predominant, whereas C. tropicalis was the yeast species most (71.4\%) frequently isolated from tracheal secretions.

The MICs for amphotericin B varied from 0.125 to $16 \mu \mathrm{g} / \mathrm{mL}$ and from 0.25 to $>64 \mu \mathrm{g} / \mathrm{mL}$ for fluconazole. The MICs capable of inhibiting between $50 \%$ and $90 \%$ of the growth of isolates of each species are listed in Table 3.

All of the $C$. albicans isolates were susceptible to amphotericin B, and $94.5 \%$ were susceptible to fluconazole. Among the samples of C. tropicalis, only one displayed resistance to amphotericin $\mathrm{B}(\mathrm{MIC}=16 \mu \mathrm{g} / \mathrm{mL})$, and one was SDD to fluconazole 
TABLE 1 - Characteristics of the patients from which positive clinical samples of Candida spp. were obtained.

\begin{tabular}{|c|c|c|c|c|c|c|c|}
\hline \multirow[b]{3}{*}{ Characteristics } & \multicolumn{6}{|c|}{ Clinical samples ${ }^{a}$} & \multirow{3}{*}{$\begin{array}{r}\text { Total } \\
\%\end{array}$} \\
\hline & \multicolumn{2}{|c|}{ urine } & \multicolumn{2}{|c|}{ blood } & \multicolumn{2}{|c|}{ tracheal secretions } & \\
\hline & $\mathrm{n}=31$ & $\%$ & $\mathrm{n}=12$ & $\%$ & $\mathrm{n}=7$ & $\%$ & \\
\hline \multicolumn{8}{|l|}{ Gender } \\
\hline male $(n=15)$ & 9 & 29.0 & 5 & 41.6 & 1 & 14.3 & 30.0 \\
\hline female $(\mathrm{n}=35)$ & 22 & 71.0 & 7 & 58.4 & 6 & 85.7 & 70.0 \\
\hline$\leq 1(\mathrm{n}=11)$ & 4 & 13.0 & 7 & 58.4 & - & - & 22.0 \\
\hline $2-20(n=4)$ & - & - & 4 & 33.3 & - & - & 8.0 \\
\hline $21-40(n=4)$ & 3 & 9.7 & - & - & 1 & 14.3 & 8.0 \\
\hline $41-60(n=8)$ & 8 & 25.7 & - & - & - & - & 16.0 \\
\hline $\operatorname{ICU}(\mathrm{n}=29)$ & 17 & 54.8 & 7 & 58.4 & 5 & 71.4 & 58.0 \\
\hline $\mathrm{GW}(\mathrm{n}=20)$ & 14 & 45.2 & 4 & 33.3 & 2 & 28.6 & 40.0 \\
\hline $\operatorname{IMC}(\mathrm{n}=1)$ & - & - & 1 & 8.3 & - & - & 2.0 \\
\hline deaths $(n=9)$ & 7 & 22.5 & 2 & 16.6 & - & - & 18.0 \\
\hline
\end{tabular}

M: male; F: female; ICU: intensive care unit; IMC: intermediate care unit; GW: general ward. ${ }^{a_{\text {values }}}$ expressed as percentages; $b_{\text {ages }}$ are given in years.

TABLE 2 - Distribution of Candida species in clinical samples obtained from hospital patients.

\begin{tabular}{|c|c|c|c|c|c|c|c|c|}
\hline \multirow{3}{*}{ Species } & \multicolumn{6}{|c|}{ Clinical samples ${ }^{\mathrm{a}}$} & & \\
\hline & \multicolumn{2}{|c|}{ urine } & \multicolumn{2}{|c|}{ blood } & \multicolumn{2}{|c|}{ tracheal secretions } & \multicolumn{2}{|c|}{ total } \\
\hline & $\mathrm{n}$ & $\%$ & $\mathrm{n}$ & $\%$ & $\mathrm{n}$ & $\%$ & $\mathrm{n}$ & $\%$ \\
\hline Candida albicans & 9 & 29.0 & 8 & 66.6 & 1 & 14.3 & 18 & 36.0 \\
\hline Candida glabrata & 9 & 29.0 & - & - & 1 & 14.3 & 10 & 20.0 \\
\hline
\end{tabular}

a numbers of isolates and percentages.

$(\mathrm{MIC}=16 \mu \mathrm{g} / \mathrm{mL})$. The other isolates were susceptible to both antifungal drugs. All isolates of the species $C$. glabrata and C. krusei were susceptible to amphotericin B, but exposure to fluconazole revealed high MICs among these isolates (Table 3).

\section{DISCUSSION}

Fungal infections are frequent complications for hospitalized patients. Candida spp. infections have increased in the last few decades, particularly those caused by NCAC species, indicating the importance of laboratory diagnoses for the correct identification of the species involved and the initiation of timely and adequate treatment ${ }^{3}$.

The data presented here included the factors of age, sex, and the hospital units in which the patients were infected. The data were similar to those of previous studies. Furnaleto et al. ${ }^{12}$ observed that infections caused by Candida spp. were more frequent in older people ( $>61$ years), those less than one year old, and among ICU patients ${ }^{19,20}$.

Hospital infections are more frequent and can often be more serious in older patients due to factors related to aging itself, the underlying disease, and hospitalization. The death rate from candidemia, however, is highest among young patients ${ }^{21}$. The occurrence of Candida spp. infections in small children often involves the colonization of their mucous membranes or skin, which puts them at risk for invasive illnesses caused by changes in their host-parasite equilibrium ${ }^{22}$. Infections caused by Candida among female patients (principally candiduria) are often associated with the presence of Candida spp. in the vaginal microbiota. The high infection percentages of ICU patients is directly related to their exposure to risk factors for fungal infection, including previous use of antibiotics, invasive 
TABLE 3 - Antifungal susceptibility profile of Candida species isolated from clinical samples and variations in the MIC, MIC ${ }_{50}$, and $\mathrm{MIC}_{90}$ of the isolates of Candida spp.

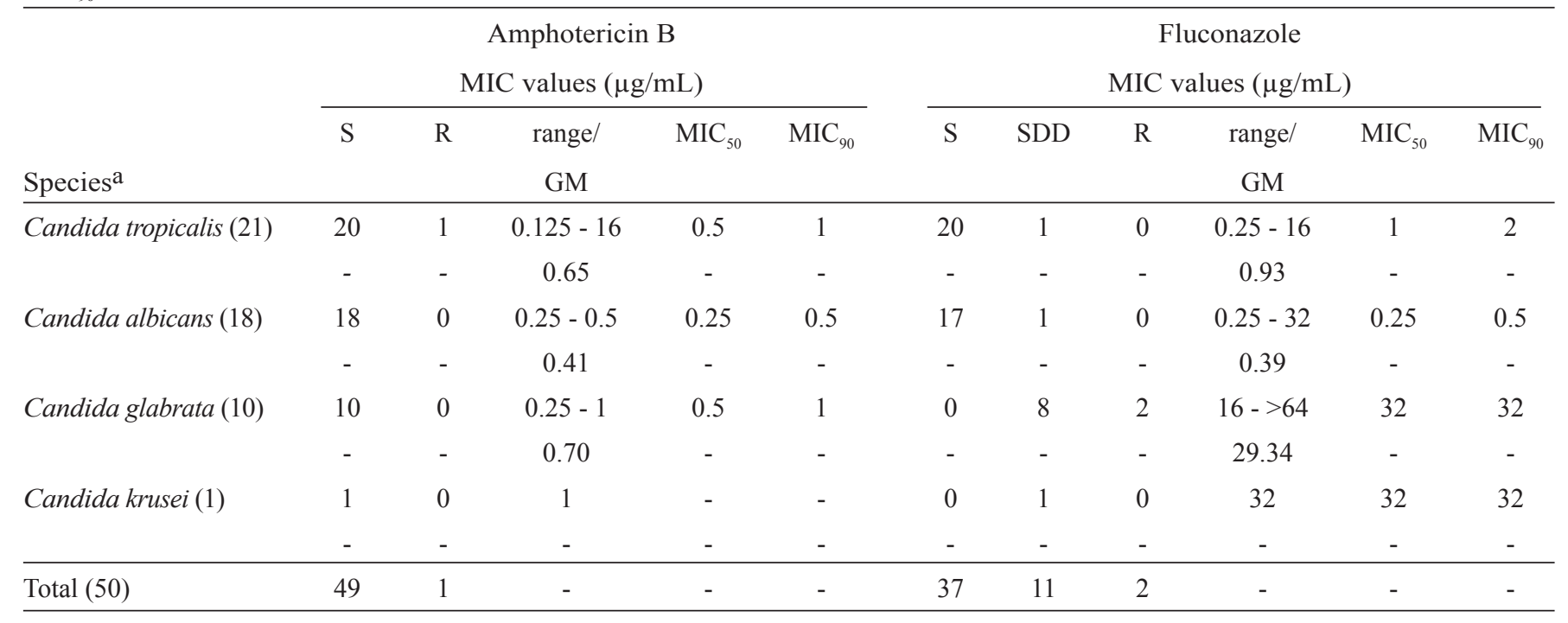

S: susceptible; SDD: dose-dependent susceptible; R: resistant; GM: geometric mean; MIC: minimum inhibitory concentration; $\mathrm{MIC}_{50}$ and $\mathrm{MIC}_{90}$ : lowest concentration capable of inhibiting growth in $50 \%$ and $90 \%$ of the isolates, respectively. ${ }^{\mathrm{n}}$ number of isolates.

procedures such as the use of central venous catheters, prolonged hospitalization periods, and weakness due to the underlying causes for their original hospitalization ${ }^{23}$.

Studies have indicated an apparent decrease in the infection rates of $C$. albicans in recent decades but an increase in infections caused by NCAC species ${ }^{8}$, which corroborates the results of the present study, in which C. albicans represented only $36 \%$ of the isolates, whereas NCAC species (C. tropicalis, C. glabrata, and C. krusei) represented the majority of isolates (64\%). These results are similar to other recent studies conducted in central-western Brazil. Yamamoto et al. ${ }^{20}$ reported a prevalence of $C$. albicans of $39 \%$ among isolates in Cuiabá, State of Mato Grosso, and other reports from the same country have indicated a predominance of NCAC species over C. albicans in clinical samples isolated from hospitalized patients ${ }^{12,24}$.

According to our results, C. tropicalis was the most frequently isolated species in hospitalized patients (42\%), mainly from urine, in contrast to the results of studies in other parts of the world, where $C$. albicans is usually predominant among hospital infections. Among urinary tract fungal infections, C. tropicalis is the second or third most frequently isolated Candida species in urine cultures ${ }^{25,26}$.

In the present study, C. albicans was the most (66.6\%) frequent species among the cases of candidemia, similar to reports from the United States, Europe, and Brazil127,28,29. However, Chang et al. ${ }^{19}$ reported a prevalence of C. albicans of $45.8 \%$ among analyzed candidemia infections at the University Hospital of the State of Mato Grosso do Sul. In Brazil and in our study, several studies have indicated $C$. tropicalis as the second most frequent isolate in cases of candidemia among hospitalized patients ${ }^{12,20,24}$. C. tropicalis is the fourth most frequent Candida species isolated in cases of candidemia in the United States ${ }^{30}$ and the third most frequent isolate in Spain ${ }^{8}$ and $\mathrm{Asia}^{6}$. The ability to detect bloodstream infections caused by Candida spp. is limited because bloodstream infections do not have any specific symptomatology and produce only low positive results in blood cultures. These limitations facilitate the spread of yeast to other organs, resulting in the worsening of the clinical situation of the patient, prolonged administration of medication, and high hospital $\operatorname{costs}^{13}$. Cases of candidemia were more frequently observed in children younger than one year.

A high sensitivity of $C$. albicans to antifungal agents was observed, corroborating other published works ${ }^{6,12,31}$. As observed in Table 3, among the NCAC species ( $\mathrm{n}=32), 31.2 \%$ of the isolates demonstrated SDD to fluconazole, with $3.1 \%$ being resistant to amphotericin B (which corroborates published reports of high resistance of these species to antifungal agents $)^{9,13}$. None of the isolates of $C$. glabrata were susceptible to fluconazole, although $80 \%$ were SDD and $20 \%$ were resistant, in agreement with the findings of other authors who described the low sensitivity of this species to triazol ${ }^{32,33}$.

Therefore, to adequately treat yeast infections in hospital environments and to control and prevent HI, the identification of Candida isolates at the species level is extremely important, and antifungal sensitivity tests are necessary.

\section{ACKNOWLEDGMENTS}

The authors would like to thank Flávia Patussi Correia Sacchi and Nathalie Gaebler Vasconcelos of the Laboratory for Clinical Analysis at the University Hospital of the Federal University at Grande Dourados for their contributions to isolating. 


\section{CONFLICT OF INTEREST}

The authors declare that there is no conflict of interest.

\section{FINANCIAL SUPPORT}

Fundação de Apoio ao Desenvolvimento do Ensino, Ciência e Tecnologia do Estado de Mato Grosso do Sul (FUNDECT) and Coordenação de Aperfeiçoamento de Pessoal de Nível Superior (CAPES).

\section{REFERENCES}

1. Fridkin SK. The changing face of fungal infections in health care settings. Clin Infect Dis 2005; 41:1455-1460.

2. Azie N, Neofytos D, Pfaller M, Meier-Kriesche HU, Quan SP, Horn D. The

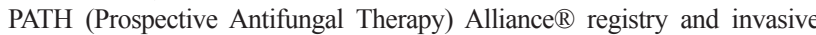
fungal infections: update 2012. Diagn Microbiol Infect Dis 2012; 73:293300 .

3. Colombo AL, Guimarães T. Epidemiologia das infecções hematogênicas por Candida spp. Rev Soc Bras Med Trop 2003; 36:599-607.

4. Alonso-Valle H, Acha O, García-Palomo JD, Fariñas-Alvarez C, FernándezMazarrasa C, Fariñas MC. Candidemia in terciary care hospital: epidemiology and factors influencing mortality. Eur J Clin Microbiol Infect Dis 2003; 22:254-257.

5. Dignani MC, Solomkin JS, Anaissie E. Candida. In: Anaissie E, McGinnis MR, Pfaller MA, editors. Med mycology. $1^{\text {st }}$. ed. Philadelphia: Churchill Livingstone, 2003; p. 195-239.

6. Chi HW, Yang YS, Shang ST, Chen KH, Yeh KM, Chang FY, et al. Candida albicans versus non-albicans bloodstream infections: The comparison of risk factors and outcome. J Microbiol Immun Infec 2011; 44:369-375.

7. Colombo AL, Nucci M, Salomão R, Branchini ML, Richtmann R, Derossi A, et al. High rate of non-albicans candidemia in Brazilian tertiary care hospitals. Diagn Microbiol Infect Dis 1999; 34:281-286.

8. Ortega M, Marco F, Soriano A, Almela M, Martínez JA, López J, et al. Candida Species bloodstream infection: epidemiology and outcome in a single institution from 1991 to 2008. J Hosp Infect 2011; 77:157-161.

9. Schmalreck AF, Willinger B, Haase G, Blum G, Lass-Flörl C, Fegeler W, et al. Species and susceptibility distribution of 1062 clinical yeast isolates to azoles, echinocandins, flucytosine and amphotericin B from a multicentre study. Mycoses 2012; 55:e124-e137.

10. Tortorano AM, Prigitano A, Dho G, Grancini A, Passera M, ECMMFIMUA Study Group. Antifungal susceptibility profiles of Candida isolates from a prospective survey of invasive fungal infections in Italian intensive care units. J Med Microbiol 2012; 61:389-393.

11. Ashley ESD, Lewis R, Lewis JS, Martin C, Andes D. Pharmacology of Systemic Antifungal Agents. Clin Infec Dis 2006; 43:S28-S39.

12. Furnaleto MC, Rota JF, Quesada RMB, Furnaleto-Maia L, Rodrigues R, Oda S, et al. Species distribution and in vitro fluconazole susceptibility of clinical Candida isolates in a Brazilian tertiary-care hospital over a 3-year period. Rev Soc Bras Med Trop 2011; 44:595-599.

13. Pfaller MA, Diekema DJ, Jones RN, Sader HS, Fluit AC, Hollis RJ, et al. International surveillance of bloodstream infections due to Candida species: frequency of occurrence and in vitro susceptibilities to fluconazole, ravuconazole and voriconazole of isolates collected from 1997 through 1999 in the SENTRY antimicrobial surveillance program. J Clin Microbiol 2001; 39:3254-3259.

14. Giolo MP, Svidzinski TIE. Fisiopatogenia, epidemiologia e diagnóstico laboratorial da candidemia. J Bras Patol Med Lab 2010; 46:225-234.
15. Yarrow D. Methods for the isolation, maintenance and identification of yeasts. In: CP Kurtzman, JW Fell, editors. The yeast, a taxonomic study. Elsevier: New York; 1998. p. 77-99.

16. Clinical and Laboratory Standards Institute (CLSI). Reference method for broth dilution antifungal susceptibility testing of yeasts: approved standard M27-A3. $3^{\text {rd. }}$. ed. Wayne: CLSI; 2008a.

17. Clinical and Laboratory Standards Institute (CLSI). Reference method for broth dilution Antifungal Susceptibility testing of yeasts; $3^{\text {rd }}$ Informational Supplement, M27-S3. Wayne: CLSI; 2008 b.

18. Yang YL, Wang AH, Wang CW, Cheng WT, Li SY, Lo HJ. Suscetibilities to amphotericin B and fluconazole of Candida species in Taiwan surveillance of antimicrobial resistance of yeasts 2006. Diag Microbiol Infect Dis 2008; 61:175-180.

19. Chang MR, Correia FP, Costa LC, Xavier PCN, Palhares DB, Taira DL, et al. Candida bloodstream infection: data from a teaching hospital in Mato Grosso do Sul, Brazil. Rev Inst Med Trop S Paulo 2008; 50:265-268.

20. Yamamoto ACA, Paula CR, Dias LB, Tadano T, Martins ERM, Amadio JVRS, et al. Epidemiological and clinical characteristics of nosocomial candidiasis in university hospitals in Cuiabá - Mato Grosso, Brazil. Rev Iberoam Micol 2012; 29: 164-168.

21. Guimarães T, Nucci M, Mendonça JS, Martinez R, Brito LR, Silva N, et al. Epidemiology and predictors of a poor outcome in elderly patients with candidemia. Int J Infect Dis 2012; 16:e442-e447.

22. Hube B. From commensal to pathogen: stage- and tissue-specific gene expression of Candida albicans. Curr Opin Microbiol 2004; 7:336-341.

23. Talarmin JP, Boutoille D, Tattevin P, Dargère S, Weinbreck P, Ansart S, et al. Epidemiology of candidemia: a one-year prospective observational study in the west of France. Med Mal Infect 2009; 39:877-885.

24. Hinrichsen SL, Falcão E, Vilella TAS, Rêgo L, Lira C, Almeida L, et al. Candidemia em hospital terciário do nordeste do Brasil. Rev Soc Bras Med Trop 2008; 41:394-398.

25. Delgado J, Calvo N, Gomis A, Pérez-Flores I, Rodríguez A, Ridao N, et al. Candiduria in renal transplant recipients: incidence, clinical repercussion, and treatment indication. Transplant Proc 2010; 42:2944-2946.

26. Jain M, Dogra V, Mishra B, Thakur A, Loomba PS, Bhargava A. Candiduria in catheterized intensive care unit patients: emerging microbiological trends. Indian J Pathol Microbiol 2011; 54:552-555.

27. Edmond MB, Wallace SE, McClish DK, Pfaller MA, Jones RN, Wenzel RP. Nosocomial bloodstream infections in United States hospitals: a threeyear analysis. Clin Infect Dis 1999; 29:239-244.

28. Tortorano AM, Pen J, Bernhardt H, Klingspor L, Kibbler CC, Faure O, et al. Epidemiology of candidaemia in Europe: results of 28-month European Confederation of Medical Mycology (ECMM) hospital-based surveillance study. Eur J Clin Microbiol Infect Dis 2004; 23:317-322.

29. Colombo AL, Nucci M, Park BJ, Nouér SA, Arthington-Skagg B, Matta DA, et al. Epidemiology of candidemia in Brazil: a nationwide sentinel surveillance of candidemia in eleven medical centers. J Clin Microbiol 2006; 44:2816-2823.

30. Wisplinghoff H, Bischoff T, Tallent SM, Seifert H, Wenzel RP, Edmond MB. Nosocomial bloodstream infections in US hospitals: analysis of 25,179 cases from a prospective nationwide surveillance study. Clin Infect Dis 2004; 39:309-317.

31. Pfaller MA, Messer SA, Moet GJ, Jones RN, Castanheira M. Candida bloodstream infections: comparison of species distribution and resistance to equinocandin and azole antifungal agents in Intensive Care Unit (ICU) and non-ICU settings in the SENTRY Antimicrobial Surveillance Program (2008-2009). Int J Antimicrob Agents 2011; 38:65-69.

32. Kiraz N, Dag I, Oz Y, Yamac M, Kiremitci A, Kasifoglu N. Correlation between broth microdilution and disk diffusion methods for antifungal susceptibility testing of caspofungin, voriconazole, amphotericin B, itraconazole and fluconazole against Candida glabrata. J Microbiol Methods 2010; 82: 136-140.

33. Singla N, Gulati N, Kaistha N, Chander J. Candida colonization in urine samples of ICU patients: determination of etiology, antifungal susceptibility testing and evaluation of associated risk factors. Mycopathologia 2012; 174:149-155. 